\title{
Ecology of cutaneous leishmaniasis in Sinai: linking parasites, vectors and hosts
}

\author{
Abdallah Mohammed Samy ${ }^{1,2}{ }^{+}$, Said Abdallah Doha ${ }^{3}$, Mohamed Amin Kenawy ${ }^{1}$ \\ ${ }^{1}$ Department of Entomology ${ }^{3}$ Research and Training Center on Vectors of Diseases, Faculty of Science, Ain Shams University, Abbassia, \\ Cairo, Egypt ${ }^{2}$ Biodiversity Institute/Department of Ecology and Evolutionary Biology, The University of Kansas, Lawrence, KS, USA
}

Cutaneous leishmaniasis (CL) is a neglected clinical form of public health importance that is quite prevalent in the northern and eastern parts of Egypt. A comprehensive study over seven years (January 2005-December 2011) was conducted to track CL transmission with respect to both sandfly vectors and animal reservoirs. The study identified six sandfly species collected from different districts in North Sinai: Phlebotomus papatasi, Phlebotomus kazeruni, Phlebotomus sergenti, Phlebotomus alexandri, Sergentomyia antennata and Sergentomyia clydei. Leishmania (-)-like flagellates were identified in 15 P. papatasi individuals (0.5\% of 3,008 dissected females). Rodent populations were sampled in the same districts where sandflies were collected and eight species were identified: Rattus norvegicus $(n=39)$, Rattus rattus frugivorous $(n=13)$, Rattus rattus alexandrinus $(n=4)$, Gerbillus pyramidum floweri $(n$ $=38)$, Gerbillus andersoni $(n=28)$, Mus musculus $(n=5)$, Meriones sacramenti $(n=22)$ and Meriones crassus $(n=$ 10). Thirty-two rodents were found to be positive for Leishmania infection (20.12\% of 159 examined rodents). Only Leishmania major was isolated and identified in $100 \%$ of the parasite samples. The diversity of both the vector and rodent populations was examined using diversity indices and clustering approaches.

Key words: sandfly - Phlebotomus - leishmaniasis - Leishmania major - Sinai - Egypt

Cutaneous leishmaniasis (CL) is a neglected clinical form that is highly prevalent in the northern and eastern parts of Egypt. Leishmania major and Leishmania tropica circulate in Sinai (Shehata et al. 2009). L. major is known to be transmitted by the sandfly Phlebotomus papatasi; however, no vector information is available in the sole report documenting L. tropica from Egypt (Shehata et al. 2009). A new focus of CL was identified on the border between Egypt and neighbouring Palestine and Israel (Jacobson 2003, Nasereddin et al. 2008). The presence of CL caused by L. tropica remains unclear with regard to the two scenarios described by Shehata et al. (2009): that historical difficulties in distinguishing L. major from L. tropica (Jacobson 2003) have masked the presence of $L$. tropica in past studies vs. that recent incursion by $L$. tropica from adjacent endemic regions is responsible for this species' recent detection.

Leishmaniasis diagnosis is a major challenge due to its diverse clinical manifestations, which make the concrete diagnosis of present and past cases difficult. However, differential diagnosis is important because other diseases with a similar clinical spectrum [e.g., leprosy, skin cancer and tuberculosis for CL, malaria and schistosomiasis for visceral leishmaniasis (VL)] often co-occur in areas

doi: 10.1590/0074-0276130426

Financial support: RTC/Vectors of Diseases, Department of Ento-

mology/Ain Shams University

+ Corresponding author: asamy.ku@gmail.com

Received 2 September 2013

Accepted 19 February 2014 of endemicity (Reithinger et al. 2007). The ability to distinguish between Leishmania species is, therefore, crucial for correct diagnosis, prognosis, treatment and control measures. In Egypt, however, little is known about parasite genotypes (Shehata et al. 1988). Recent studies have depended on internal transcribed spacer (ITS)-1 sequences to differentiate between imported and autochthonous infections (Jacobson et al. 2003); other methods can be used to complement ITS-1 sequences, such as microsatellites and kinetoplastid DNA (Schwenkenbecher et al. 2006). Epidemics of leishmaniasis are known to occur in many foci throughout the world (Seaman et al. 1996, Rodríguez-Barraquer et al. 2008, Wang et al. 2010). Nonetheless, molecular studies to date have not often taken advantage of phylogenetic or population genetic approaches for data analysis in Middle Eastern countries (Tibayrenc 2005, Nasereddin et al. 2008), even though successful examples are available from other locations (Katakura 2009, Miranda et al. 2009). Consequently, CL public health impacts have been underestimated, as a substantial number of cases go unrecorded: approximately 1.5-2 million new cases are estimated to occur annually, but only 600,000 are officially declared (WHO 2008).

Leishmaniasis dynamics have changed in response to environmental, demographic and human behavioural factors (Campbell-Lendrum et al. 2001). The response of leishmaniasis to environmental changes may result from a change in the geographic distribution of the potential vectors/animal reservoir, either by the identification of new habitats or by range shifts for the same species (Parmesan 2006). In Egypt, however, CL cases are still underestimated due to the Bedouin traditions of preventing females from visiting clinics and their dependence on routine heat therapy for the treatment of CL (Samy 2009). 
Here, we report our findings from a comprehensive study conducted over seven years to track the CL transmission cycle. Our findings suggest the continuous circulation of L. major in Sinai and identify both the vector(s) and animal reservoir(s), providing new insight into the ecology of $\mathrm{CL}$ and disease transmission in Egypt.

\section{MATERIALS AND METHODS}

Study sites - North Sinai is located in the northeastern part of Egypt $\left(30.5^{\circ} \mathrm{N} 33.6^{\circ} \mathrm{E}\right)$, marking the point of connection between Asia and Africa. North Sinai is bordered by the Gulf of Suez, the Red Sea and the Mediterranean Sea and is inhabited mainly by Bedouins. The regions comprise the following districts: El-Hassana, Beer El Abd, Nekhel, Sheikh Zuweid, Beer Lehfen and Rafah (Fig. 1). The study sites were selected based on the distribution of CL cases in Sinai to understand the potential role of both the sandfly and rodent in the dynamics of Leishmania transmission (Samy 2009, Ministry of Health of Egypt, unpublished observations). These districts have diverse geographic and demographic characteristics and their "crossroads" nature and environmental changes may create new potential risks for disease transmission. The weather in North Sinai is characterised as hot and dry, with marked differences in temperature between day and night. Dramatic weather-related changes, as presented by the annual averages of environmental factors during the study period from January 2005-December 2011, are listed in Supplementary data and some habitats are illustrated in Fig. 2.

Sandfly collection and processing - Sandfly collection was carried out using sticky paper traps and CDC light traps (LT) (John W Hock, Gainesville, FL, USA) for eight nights/year. Five collection sites were selected randomly to represent each district in the study; $10 \mathrm{CDC}$ LT and 50 sticky traps (ST) were used for each study district (2 CDC and 10 ST/collection site). The collec- tion sites were chosen to represent the most productive ones for fly capture based on our preliminary studies conducted in different sites of Sinai. The traps were set before sunset and recovered the next morning. The recovered ST were placed in labelled plastic bags, transported to a temporary field laboratory and then sent to the Research and Training Centre Laboratory (RTC) of Ain Shams University, Cairo for processing. Dead flies were stored in $70 \%$ alcohol for species identification. The live flies captured by the CDC traps were collected with a mechanical aspirator and dissected in saline with $50 \mathrm{U} / \mathrm{mL}$ of amikacin sulphate on a glass slide. The digestive tract was examined under an optical microscope with 400X magnification to identify flies harbouring parasites in their gut and for species identification via morphological keys (Lane 1986). The identification of Phlebotomus sergenti followed Depaquit et al. (1998). Female digestive tracts that had flagellates were transferred to an Eppendorf tube with saline containing $50 \mathrm{U} /$ $\mathrm{mL}$ of amikacin sulphate and then inoculated into Novy Mac Neal Nicolle (NNN) culture medium.

Rodent trapping and processing - Rodents were trapped using wire-box rodent traps (Morsy et al. 1992, Hamadto et al. 2007) (Fig. 2A) placed adjacent to outdoor and indoor rodent burrows. Each district was represented by five-eight collection sites where 10-18 traps each were used; the traps were set before sunset and recovered the next morning. The rodents were identified using regional taxonomic keys (Osborn \& Helmy 1980) and then transported to the Ain Shams animal facility where they were maintained for at least six months to observe the development of any characteristic Leishmania lesions. Full-thickness punch-biopsies were removed from the border of suspected lesions and processed for parasite isolation in NNN medium. Giemsa-stained impression smears were also performed for the lesions and

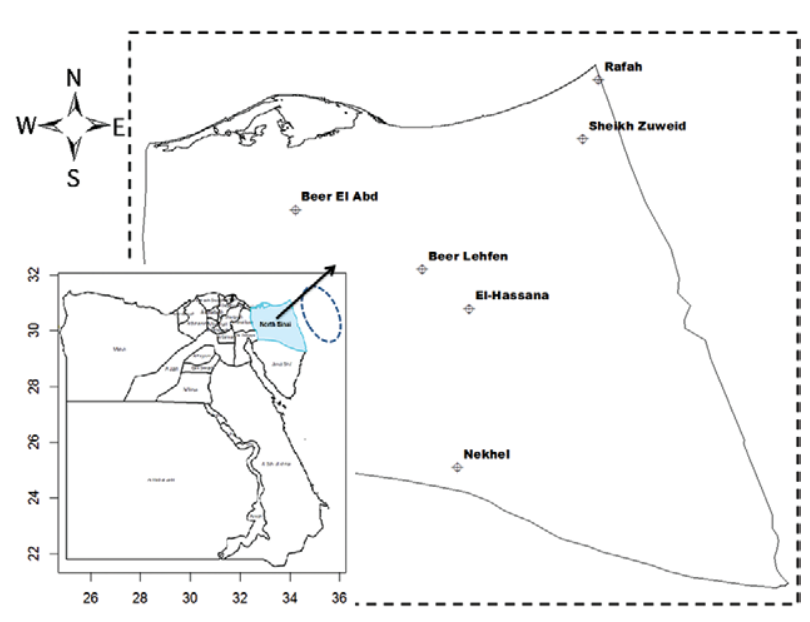

Fig. 1: regional and local map of the study sites in North Sinai. The six districts of North Sinai are denoted by black dots and Egypt with the black solid line. The dotted circular represents the neighbouring Palestine territories.

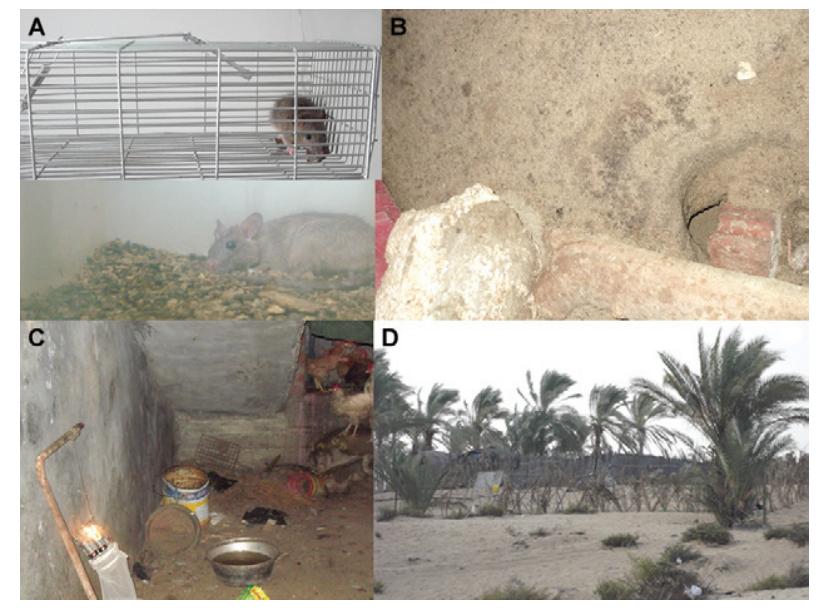

Fig. 2: sampling localities showing different habitat types. A: wirebox rodent traps used during the study with an individual rodent collected during the study; B: rodent burrows; C: habitat of low hygiene support rodent and sandfly populations; D: a sample of the outdoor habitats sampled in the study. 
examined for the presence of Leishmania amastigotes (Soliman 2006). All care and use of animals was conducted in compliance with the Animal Welfare Act and in accordance with the principles set forth in the Guide for the Care and Use of Laboratory Animals, Institute of Laboratory Guiding Principles for Biomedical Research Involving Animals (CIOMS 1985).

Molecular characterisation of Leishmania cultures - Isolates from rodents and sandflies with suspected Leishmania parasites were initially inoculated from tissue samples and maintained in culture medium through subculture passages in NNN culture medium with 500 IU penicillin $\mathrm{G} / \mathrm{mL}$ of blood. Promastigotes from positive cultures were transferred to glass vials containing Schneider's Drosophila cell culture medium supplemented with $10 \%$ fetal calf serum (Sigma, Saint Louis, MO, USA and Gibco-BRL, Gaithersburg, MD, USA) for mass rearing.

One millilitre of each high-density $\left(\sim 1 \times 10^{6}\right.$ cells $\left.\mathrm{mL}^{-1}\right)$ Leishmania culture was concentrated by centrifugation at $12,000 \mathrm{~g}$ for $10 \mathrm{~min}$. DNA was extracted from the pellet using the Qiagen DNA Mini Kit (Qiagen, Valencia, CA, USA). Approximately $25 \mu \mathrm{L}$ of the culture pellet was transferred to a sterile $1.5 \mathrm{~mL}$ tube, extracted as per the protocol instructions and eluted in $100 \mu \mathrm{L}$ elution buffer. Proteinase $\mathrm{K}$ digestion was performed overnight at $56^{\circ} \mathrm{C}$. The ribosomal ITS-1 was amplified using the primer pair L5.8S and LITSR (El Tai et al. 2000). Amplicons were analysed on 1.5\% agarose gels by electrophoresis and visualised by ultraviolet light. A reaction was considered positive when a band of the correct size (300-350 bp) was observed. The polymerase chain reaction $(\mathrm{PCR})$ product was digested with the restriction endonuclease HaeIII. The restriction fragment length polymorphism-PCR approach was applied for the detection and identification of Leishmania parasites in the rodent and sandfly isolates. Fragments were separated by electrophoresis on $2.5 \%$ agarose gels and compared with those of reference strains of L. major (MHOM/EG/06/ RTC-63) and L. tropica (MGER/EG/06/RTC-74) using distilled water as a negative control.

Statistical analysis - Data were analysed using SAS JMP Statistical Discovery v.8.0.2. The BioDiversity Professional statistics analysis software (McAleece et al. 1997) was used to estimate the biodiversity index for both the sandfly and rodent populations. The Bray-Curtis similarity was used in cluster analysis to estimate the similarity between the sandfly or rodent populations across different districts of North Sinai, Egypt. Chi-squared analysis was used to test the deviation of the resulting fly sex ratios (female:male) from the expected 1:1 ratio.

Ethics - Verbal informed consent was obtained from the heads of the households from which sandflies were collected. We provided detailed information about the vector-borne diseases with a special focus on leishmaniasis risk, vectors and reservoirs in language understandable to the local Bedouins communities. We also provided information for community-based control measures to help the communities to protect themselves against disease risk.
The views expressed in this article are those of the authors and do not necessarily reflect the official policy or position of the Egyptian or the United States of America Government. The experiments reported herein were conducted in compliance with the Animal Welfare Act and in accordance with the principles set forth in the Guide for the Care and Use of Laboratory Animals, Institute of Laboratory Animals Resources, National Research Council, National Academy Press and Council for International Organizations of Medical Sciences.

\section{RESULTS}

Sandfly species composition - A total of 9,849 sandflies were collected from different districts during the study (Table I) on 56 nights using $480 \mathrm{CDC}$ and 2,800 ST. Males comprised $62.8 \%(n=6184)$ of the catch (female:male ratio of 0.6 ). A total of $23.3 \%$ (404 males, 1,892 females) of the collected flies were caught indoors and the rest of the flies were caught outdoors and from around the rodent burrows. These flies represented six species of two genera: P. (Phlebotomus) papatasi (Scopoli), Phlebotomus (Paraphlebotomus) kazeruni (Theodor \& Mesghali), P. (Paraphlebotomus) sergenti (Parrot), Phlebotomus (Paraphlebotomus) alexandri (Sinton), Sergentomyia (Sergentomyia) antennata (Newst.) and Sergentomyia (Sintonius) clydei (Sinton). The predominant species was $P$. papatasi $(83.5 \%, 8,221$ flies), whereas $P$. sergenti and $P$. kazeruni represented $9 \%$ and $3.3 \%$ of the total, respectively. All the remaining species represented only $4.2 \%$. P. alexandri, the VL vector, represented only $1 \%$ and was found in limited distribution in Nekhel.

Sandfly sex ratios - Sex ratios (females:males) showed that males were overall approximately twice as common, with an overall sex ratio of 1:1.7. There was a difference between the sex ratios of different sandfly species using both trapping methods; the CDC traps collected more females than males for both the P. papatasi and P. kazeruni collections, but more males were collected from both species when the sticky paper traps were used (Table I). Both trapping methods collected more males of $P$. sergenti, $P$. alexandri, S. antennata and $S$. clydei. The chi-squared analysis revealed a significant difference (p $=0.00$ ) between the overall sex ratio (female:male) and the equilibrium 1:1 sex ratio for all species, except with regard to the CDC collection of P. kazeruni $(\mathrm{p}=0.08), S$. antennata $(\mathrm{p}=0.32)$ and $S$. clydei $(\mathrm{p}=0.25)$.

Sandfly natural infection - The results of sandfly dissections revealed the presence of Leishmania-like flagellates in 15 P. papatasi specimens $(0.5 \%$ of 3,008 dissected females). None of the P. kazeruni, P. sergenti and $P$. alexandri individuals were infected (Table II). There was a significant difference in the infection rate between the different districts $(\mathrm{p}<0.05)$; the highest infection rates were in Beer Lehfen $(0.73 \%)$ and Rafah $(0.72 \%)$, whereas the infection rates in Nekhel and El-Hassana were low $(0.37 \%$ and $0.26 \%$, respectively). All the females collected from Beer El Abd and Sheikh Zuweid were negative for infection. The Leishmania-like flagellates were inoculated into NNN medium and the parasites survived in only six out of 15 culture passages. 
Rodent species composition and natural infections - A total of 159 individual rodents were collected from different districts (Table III). These rodents represented eight species: Rattus norvegicus $(\mathrm{n}=39)$, Rattus rattus frugivorous $(\mathrm{n}=13)$, Rattus rattus alexandrinus $(\mathrm{n}=4)$, Gerbillus pyramidum floweri $(\mathrm{n}=38)$, Gerbillus andersoni $(\mathrm{n}=28)$, Mus musculus $(\mathrm{n}=5)$, Meriones sacramenti $(\mathrm{n}=22)$ and Meriones crassus $(\mathrm{n}=$ 10). Thirty-two rodents were found to be positive for infection by amastigote impression smear testing: $G$. p. floweri $(\mathrm{n}=16), G$. andersoni $(\mathrm{n}=5), R$. norvegicus $(\mathrm{n}=7), R . r$. frugivorous $(\mathrm{n}=3)$ and $R . r$. alexandrinus $(\mathrm{n}=1)$ (Table III). None of the M. musculus, $M$. sacramenti and $M$. crassus specimens were positive for Leishmania infection. The infected rodents included rodents collected from El-Hassana $(1 R$. $r$. alexandri$n u s)$, Rafah (7 R. norvegicus, 14 G. p. floweri and 5 G. andersoni) and Beer Lehfen ( $3 R$. r. frugivorous and 2 G. p. floweri). No positive infections were found in the rodents collected from the Nekhel, Beer El-Abd and Sheikh Zuweid. All rodent samples were inoculated into NNN medium and the parasites survived in 29 out of 32 culture passages.

Sandfly, rodent diversity and habitat clustering: sandfly species diversity - Both Simpson diversity and Berger-Parker dominance indices revealed different diversity between the different districts, with the highest overall diversity in Nehkel and Beer El Abd; the least diverse site was Sheikh Zuweid, where P. papatasi was the only species occurring at this site (Fig. 3A).
Rodent species diversity - All districts sampled in the study had a different diversity index based on both Shannon $\left(\mathrm{H}^{\prime}\right)$ and Berger-Parker dominance indices of rodent populations (Fig. 3B). The highest overall diversity index was that of Rafah $\left(1 / \mathrm{d}=3.412, \mathrm{H}^{\star}=0.675\right)$. Both Nekhel and Beer Lehfen had higher diversity indices compared to El-Hassana, Beer El Abd and Sheikh Zuweid.

Habitat clustering - Bray Curtis cluster analysis of the different districts in North Sinai revealed levels of similarity between the habitats clusters. Based on the sandflies collected from the different districts, two clusters were identified: Sheikh Zuweid and Beer El Abd formed a distinct cluster separated from the rest of the districts, which comprised a different cluster (Fig. 4A). However, the cluster analysis based on rodent data revealed different cluster patterns than those produced by the sandfly data, with both Beer Lehfen and Rafah forming a distinct cluster and the other districts comprising another cluster in which Beer El Abd was separated from the lower part of the core (Fig. 4B). Finally, the bray Curtis analysis for the combination of the sandfly and rodent data formed two distinct clusters: one included both Sheikh Zuweid and Beer El Abd and the second cluster included the other districts, with Rafah separated from the lower part of the core (Fig. 4C).

Leishmania identification and characterisation Thirty-five samples from both the infected sandfly $P$. papatasi $(\mathrm{n}=6)$ and rodent reservoirs $(\mathrm{n}=29)$ produced viable cultures in NNN medium. All of these samples

\section{TABLE I}

Phlebotomine sandflies collected by CDC light traps (LT) and sticky paper traps (ST) from six districts of North Sinai, Egypt, from January 2005-December 2011

\begin{tabular}{|c|c|c|c|c|c|c|c|c|c|}
\hline \multirow[b]{2}{*}{ Species } & \multirow[b]{2}{*}{$\begin{array}{l}\text { Collection } \\
\text { method }\end{array}$} & \multirow[b]{2}{*}{$\begin{array}{c}\text { El } \\
\text { Hassana }\end{array}$} & \multicolumn{7}{|c|}{$\begin{array}{l}\text { Number of collected flies } \\
\qquad(\mathrm{F}: \mathrm{M})\end{array}$} \\
\hline & & & Nekhel & Rafah & $\begin{array}{l}\text { Beer } \\
\text { El Abd }\end{array}$ & $\begin{array}{c}\text { Beer } \\
\text { Lehfen }\end{array}$ & $\begin{array}{l}\text { Seikh } \\
\text { Zuweid }\end{array}$ & Total & $\begin{array}{l}\text { Ratio } \\
\text { (F:M) }\end{array}$ \\
\hline Phlebotomus papatasi & $\begin{array}{l}\text { LT } \\
\text { ST }\end{array}$ & $\begin{array}{c}383 / 142 \\
141 / 1,069\end{array}$ & $\begin{array}{l}813 / 156 \\
121 / 855\end{array}$ & $\begin{array}{l}966 / 231 \\
85 / 1,336\end{array}$ & $\begin{array}{l}17 / 44 \\
25 / 69\end{array}$ & $\begin{array}{l}546 / 358 \\
88 / 663\end{array}$ & $\begin{array}{l}31 / 17 \\
4 / 61\end{array}$ & $\begin{array}{l}2,756 / 948 \\
464 / 4,053\end{array}$ & $\begin{array}{l}2.9: 1 \\
1: 8.7\end{array}$ \\
\hline Phlebotomus kazeruni & $\begin{array}{l}\text { LT } \\
\text { ST }\end{array}$ & $\begin{array}{l}\mathrm{NA} / \mathrm{NA} \\
\mathrm{NA} / \mathrm{NA}\end{array}$ & $\begin{array}{c}29 / 17 \\
52 / 225\end{array}$ & $\begin{array}{l}\text { NA/NA } \\
\text { NA/NA }\end{array}$ & $\begin{array}{l}\mathrm{NA} / \mathrm{NA} \\
\mathrm{NA} / \mathrm{NA}\end{array}$ & $\begin{array}{l}\mathrm{NA} / \mathrm{NA} \\
\mathrm{NA} / \mathrm{NA}\end{array}$ & $\begin{array}{l}\mathrm{NA} / \mathrm{NA} \\
\mathrm{NA} / \mathrm{NA}\end{array}$ & $\begin{array}{c}29 / 17 \\
52 / 225\end{array}$ & $\begin{array}{l}1.7: 1 \\
1: 4.3\end{array}$ \\
\hline Phlebotomus sergenti & $\begin{array}{l}\text { LT } \\
\text { ST }\end{array}$ & $\begin{array}{c}24 / 23 \\
2 / 98\end{array}$ & $\begin{array}{l}45 / 126 \\
81 / 221\end{array}$ & $\begin{array}{l}14 / 73 \\
77 / 43\end{array}$ & $\begin{array}{l}\mathrm{NA} / \mathrm{NA} \\
\mathrm{NA} / \mathrm{NA}\end{array}$ & $\begin{array}{l}5 / 17 \\
2 / 37\end{array}$ & $\begin{array}{l}\mathrm{NA} / \mathrm{NA} \\
\mathrm{NA} / \mathrm{NA}\end{array}$ & $\begin{array}{c}88 / 239 \\
162 / 399\end{array}$ & $\begin{array}{l}1: 2.7 \\
1: 2.4\end{array}$ \\
\hline Phlebotomus alexandri & $\begin{array}{l}\text { LT } \\
\text { ST }\end{array}$ & $\begin{array}{l}\text { NA/NA } \\
\text { NA/NA }\end{array}$ & $\begin{array}{c}26 / 43 \\
0 / 33\end{array}$ & $\begin{array}{l}\text { NA/NA } \\
\text { NA/NA }\end{array}$ & $\begin{array}{l}\text { NA/NA } \\
\text { NA/NA }\end{array}$ & $\begin{array}{l}\text { NA/NA } \\
\text { NA/NA }\end{array}$ & $\begin{array}{l}\text { NA/NA } \\
\text { NA/NA }\end{array}$ & $\begin{array}{c}26 / 43 \\
0 / 33\end{array}$ & $\begin{array}{c}1: 1.6 \\
0\end{array}$ \\
\hline Sergentomyia antennata & $\begin{array}{l}\text { LT } \\
\text { ST }\end{array}$ & $\begin{array}{c}3 / 1 \\
1 / 20\end{array}$ & $\begin{array}{c}4 / 4 \\
27 / 33\end{array}$ & $\begin{array}{l}0 / 2 \\
1 / 4\end{array}$ & $\begin{array}{l}3 / 7 \\
4 / 19\end{array}$ & $\begin{array}{c}0 / 1 \\
0 / 12\end{array}$ & $\begin{array}{l}\text { NA/NA } \\
\text { NA/NA }\end{array}$ & $\begin{array}{l}10 / 15 \\
33 / 88\end{array}$ & $\begin{array}{l}1: 1.5 \\
1: 2.7\end{array}$ \\
\hline Sergentomyia clydei & $\begin{array}{l}\text { LT } \\
\text { ST }\end{array}$ & $\begin{array}{c}1 / 2 \\
10 / 21\end{array}$ & $\begin{array}{c}\text { NA/NA } \\
18 / 29\end{array}$ & $\begin{array}{c}\text { NA/NA } \\
2 / 15\end{array}$ & $\begin{array}{c}3 / 6 \\
10 / 47\end{array}$ & $\begin{array}{c}\text { NA/NA } \\
1 / 4\end{array}$ & $\begin{array}{l}\text { NA/NA } \\
\text { NA/NA }\end{array}$ & $\begin{array}{c}4 / 8 \\
41 / 116\end{array}$ & $\begin{array}{c}1: 2 \\
1: 2.8\end{array}$ \\
\hline Total & $\begin{array}{l}\text { LT } \\
\text { ST }\end{array}$ & $\begin{array}{c}411 / 168 \\
154 / 1,208\end{array}$ & $\begin{array}{c}917 / 346 \\
299 / 1,396\end{array}$ & $\begin{array}{c}980 / 306 \\
165 / 1,398\end{array}$ & $\begin{array}{c}23 / 57 \\
39 / 135\end{array}$ & $\begin{array}{c}551 / 376 \\
91 / 716\end{array}$ & $\begin{array}{c}31 / 17 \\
4 / 61\end{array}$ & $\begin{array}{c}2,913 / 1,270 \\
752 / 4,914\end{array}$ & $\begin{array}{l}2.3: 1 \\
1: 6.5\end{array}$ \\
\hline
\end{tabular}

F: female; M: male; NA: not available. 
were tested using standard ITS-1-PCR. These samples were found to be positive for L. major DNA only (Supplementary data). L. major was recovered from six $P$. papatasi individuals collected from Rafah. Twenty-nine rodent samples found to be positive for $L$. major were $R$. norvegicus $(\mathrm{n}=7), R$. r. frugivorous $(\mathrm{n}=3), R$. r. alexandrinus $(\mathrm{n}=1), G$. p. floweri $(\mathrm{n}=13)$ and $G$. andersoni $(\mathrm{n}$ $=5$ ). All L. major-infected rodents were collected from the Rafah $(\mathrm{n}=23)$, Beer Lehfen $(\mathrm{n}=5)$ and El-Hassana $(n=1)$, with no evidence for the presence of infections in the Beer El Abd, Nekhel and Sheikh Zuweid.

\section{DISCUSSION}

This study represents a comprehensive report of seven years in North Sinai and provides evidence for the circulation of only one species of the Leishmania parasite. Previous studies in Egypt reported the presence of only L. major circulating in Sinai (Wahba et al. 1990, Fryauff et al. 1993, Kamal et al. 2003), though the most recent study in Sinai reported the incursion of CL caused by L. tropica in a remote border area of North Sinai on the
Egyptian-Palestinian border. The possibility of the incursion of L. tropica from neighbouring countries could not be excluded according to a recent study (Shehata et al. 2009). Therefore, we carried out our study to reveal insight into the ecological system for CL transmission with regard to sandflies and rodents by examining of several criteria used by the WHO to implicate either the vector(s) or reservoir(s).

There are several criteria adopted by the World Health Organization (WHO) to implicate $P$. papatasi as the potential vector for circulation of leishmaniasis in Sinai, including anthropophilic behaviour, the ability to feed on the reservoir host(s), the presence of natural infections, the ability to support the growth of the parasite and the ability to transmit the parasite by bites (WHO 2010). The current study identified six species of sandfly. However, the results revealed no evidence for the presence of infection in most of the sandflies collected; for instance, the only species found infected with Leishmania promastigotes was $P$. papatasi, with an infection rate close to $0.5 \%$. The sandfly $P$. papatasi, the potential

TABLE II

Number and species of Phlebotomus () dissected and naturally infected with Leishmania major in different districts of North Sinai, Egypt, from 2005-2011

\begin{tabular}{|c|c|c|c|c|c|c|}
\hline Species & $\begin{array}{c}\text { El Hassana } \\
\text { n }(\%)\end{array}$ & $\begin{array}{l}\text { Nekhel } \\
\text { n }(\%)\end{array}$ & $\begin{array}{l}\text { Rafah } \\
\text { n (\%) }\end{array}$ & $\begin{array}{c}\text { Beer El Abd } \\
\text { n }(\%)\end{array}$ & $\begin{array}{c}\text { Beer Lehfen } \\
\text { n }(\%)\end{array}$ & $\begin{array}{c}\text { Sheikh Zuweid } \\
\text { n (\%) }\end{array}$ \\
\hline Phlebotomus papatasi & $383(0.26)$ & $813(0.37)$ & $966(0.72)$ & $17(0)$ & $546(0.73)$ & $31(0)$ \\
\hline Phlebotomus kazeruni & $0(0)$ & $29(0)$ & $0(0)$ & $0(0)$ & $0(0)$ & $0(0)$ \\
\hline Phlebotomus sergenti & $24(0)$ & $126(0)$ & $73(0)$ & $0(0)$ & $5(0)$ & $0(0)$ \\
\hline Phlebotomus alexandri & $0(0)$ & $26(0)$ & $0(0)$ & $0(0)$ & $0(0)$ & $0(0)$ \\
\hline Total & $407(0.24)$ & $994(0.30)$ & $1,039(0.67)$ & $17(0)$ & $551(0.72)$ & $31(0)$ \\
\hline
\end{tabular}

TABLE III

Number of rodents trapped in different districts of North Sinai, Egypt, from 2005-2011 and infection percentages with Leishmania

\begin{tabular}{|c|c|c|c|c|c|c|c|}
\hline Species & $\begin{array}{c}\text { El Hassana } \\
\text { n }(\%)\end{array}$ & $\begin{array}{c}\text { Nekhel } \\
\text { n }(\%)\end{array}$ & $\begin{array}{l}\text { Rafah } \\
\text { n (\%) }\end{array}$ & $\begin{array}{c}\text { Beer El Abd } \\
\text { n }(\%)\end{array}$ & $\begin{array}{c}\text { Beer Lehfen } \\
n(\%)\end{array}$ & $\begin{array}{l}\text { Sheikh } \\
\text { Zuweid } \\
\text { n (\%) }\end{array}$ & $\begin{array}{l}\text { Total } \\
\text { n }(\%)\end{array}$ \\
\hline Rattus norvegicus & $1(0)$ & $0(0)$ & $34(20.58)$ & $1(0)$ & $0(0)$ & $3(0)$ & $39(18)$ \\
\hline Rattus rattus frugivorous & $2(0)$ & $1(0)$ & $0(0)$ & $1(0)$ & $9(33.33)$ & $0(0)$ & $13(23.07)$ \\
\hline Rattus rattus alexandrinus & $3(33.33)$ & $1(0)$ & $0(0)$ & $0(0)$ & $0(0)$ & $0(0)$ & $4(25)$ \\
\hline Gerbillus pyramidum floweri & $0(0)$ & $0(0)$ & $31(45.16)$ & $0(0)$ & $7(28.57)$ & $0(0)$ & $38(42.10)$ \\
\hline Gerbillus andersoni & $0(0)$ & $0(0)$ & $23(21.74)$ & $0(0)$ & $1(0)$ & $4(0)$ & $28(17.85)$ \\
\hline Mus musculus & $2(0)$ & $1(0)$ & $1(0)$ & $0(0)$ & $0(0)$ & $1(0)$ & $5(0)$ \\
\hline Meriones sacramenti & $0(0)$ & $0(0)$ & $19(0)$ & $0(0)$ & $3(0)$ & $0(0)$ & $22(0)$ \\
\hline Meriones crassus & $0(0)$ & $0(0)$ & $8(0)$ & $0(0)$ & $1(0)$ & $1(0)$ & $10(0)$ \\
\hline Total & $8(12.5)$ & $3(0)$ & $116(22.41)$ & $2(0)$ & $21(21.73)$ & $9(0)$ & $159(20.12)$ \\
\hline
\end{tabular}


vector of L. major in the Sinai Peninsula (Wahba et al. 1990, Shehata et al. 2009), was the most prevalent sandfly in our catches. In the current study, most $P$. papatasi females were caught indoors and in large numbers, whereas, more males were collected outdoors. The difference in the indoor and outdoor catches reported here might suggest that female $P$. papatasi is more endophagic compared to $P$. sergenti, $P$. kazeruni and $P$. alexan$d r i$. There was a significant difference in the infection rates of the sandflies between different study districts, which might be attributed to the host preference of $P$. papatasi for different vertebrates. The host preference is influenced by the availability of hosts, for example, $P$. papatasi in Beer Lehfen and Rafah had infection rates approximately $0.73 \%$ and $0.72 \%$, respectively, correlating with the high density of gerbils at both sites.

To understand CL eco-epidemiology, the ecology of the animal reservoir populations and their roles in disease transmission were also considered in our study. The most predominant species sampled in all the districts was $R$. norvegicus, previously identified in similar habitats in Sinai as a potential leishmaniasis reservoir host (Morsy et al. 1992). However, the current study revealed the presence of infections in G. p. floweri, R. rattus and $G$. andersoni; infections were also recovered from $R$. norvegicus. Similar observations were reported in different sites in Egypt (Morsy et al. 1992, Fryauff et al. 1993), but, interestingly, these observations also refer to the difference in the eco-epidemiology of CL in Egypt and other countries; for instance, Jordan and Morocco,
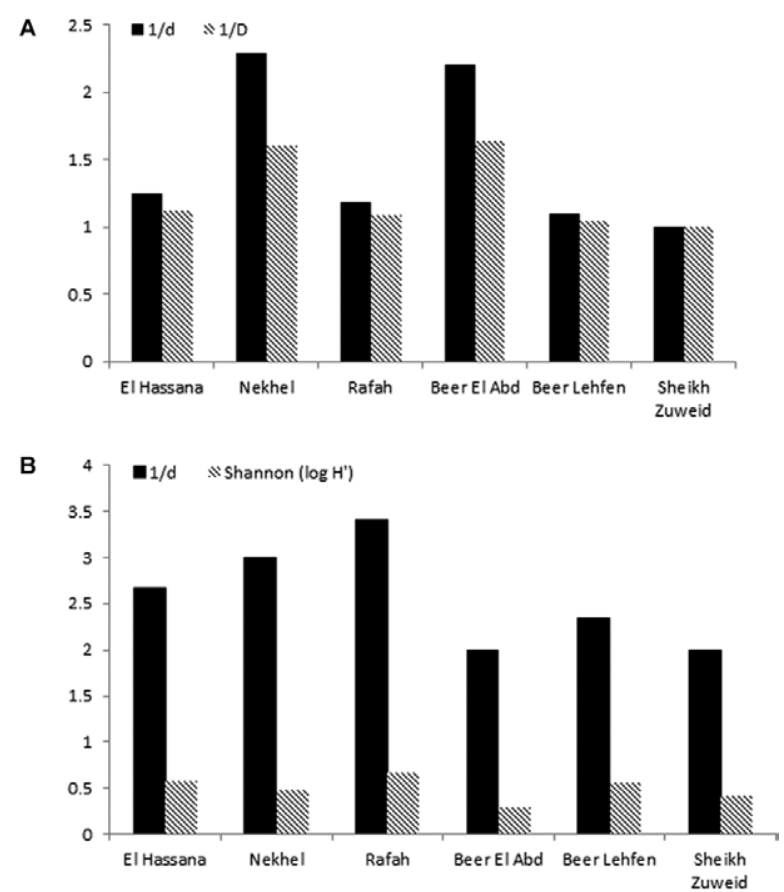

Fig. 3: biodiversity index of both the sandfly and rodent populations collected from six districts of North Sinai. A: the Simpson (1-D) and Berger-Parker dominance biodiversity index for the sandfly species (1/d); B: the Shannon (H') and Berger-Parker dominance biodiversity index for the rodent species. where Psammomys obesus was identified as the potential animal reservoir (Saliba et al. 1994, WHO 2010). The burrows of $P$. obesus are identified by halophytic vegetation and by the remnants of plant material at the entrances (WHO 2010). The structure of habitats in the six districts of the current study was relatively similar to the $P$. obesus habitat, but with no record for the species during the seven years of collection. Several criteria were also proposed by the WHO for the implication of animal reservoirs (WHO 2010) with CL transmission; one such criterion was fulfilled by isolating the parasite from wild rodents with positive infections collected from different sites in the study. Secondly, the parasite was found to be identical to that isolated from patients attending clinics in North Sinai communities (AM Samy, unpublished observations). Some criteria depend on the availability of the parasite in the skin in sufficient numbers for the sandfly to transmit. Other criteria must be investigated through experimental infection trials (Svobodova et al. 2006) to infer the potential role of these animals in the dynamics of this disease.

Throughout the late phases of our study, we used cluster analysis to infer similarity between the habitats using the data from the collection of sandflies, rodents or the combination of both. Interestingly, the areas

A
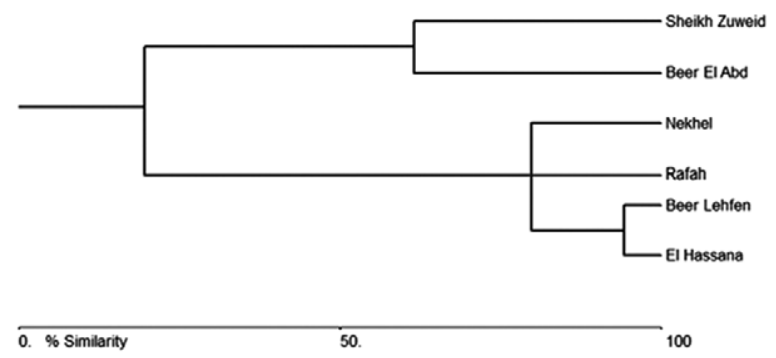

B
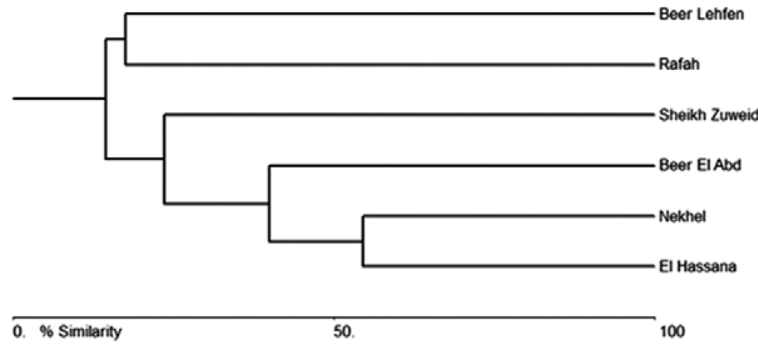

C

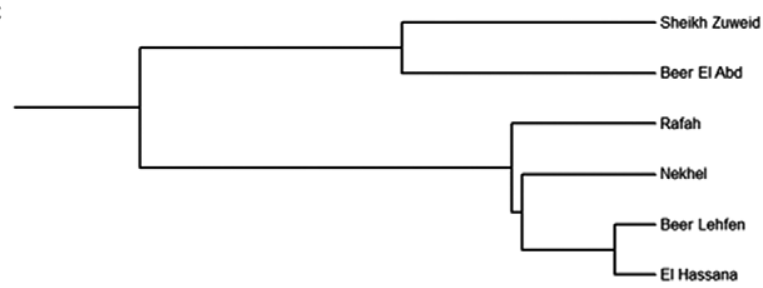

Fig. 4: dendrogram from Bray-Curtis cluster analysis based on the sandfly populations data (A), rodents populations data in six districts of Sinai Peninsula (B) and both the sandfly and rodents populations data $(\mathrm{C})$. 
identified to have disease risk formed a distinct cluster, for instance, the distinct cluster that included Rafah, Nekhel, Beer Lehfen and El Hassana (Fig. 4C). These observations revealed the importance of multivariate methods in the study of disease ecology and in inferring the area with a favourable habitat for CL circulation. One of the interesting findings of this study was the presence of infections in different animal reservoirs that were not necessarily previously known as potential reservoirs (Morsy et al. 1992, Shehata et al. 2009). These changes in the animal hosts may be a response to climate change, especially in the presence of continuous heavy rains and floods in Sinai. These environmental changes coincided with the increase in CL incidence in Sinai due to a change in the vector and rodent populations and consequently a change in the disease dynamics in the area.

Our report identified the presence of only L. major, whereas no L. tropica was detected during seven years of observations in the study areas. Previous detections of L. tropica (Shehata et al. 2009) may be allochthonous, i.e., the parasite may have originated from other sites where L. tropica is established (Jacobson et al. 2003, Vinitsky et al. 2010). P. sergenti, the presumed vector of L. tropica, was found in this study, though we found no rock hyraxes, the main L. tropica reservoir in countries including Israel and Kenya (Mebrahtu et al. 1992, Svobodova et al. 2006). Other factors that could mask the dynamics of L. tropica transmission might include differences in the seasonality of vectors or distinct reservoir populations for different transmission cycles (Faulde et al. 2008).

L. major infections circulate in the country through different seasons of the year, with three incidence peaks in November, March and August and few sporadic cases were reported during the rest of the year. These peaks correspond to the time after the peaks of sandfly abundance (Samy 2009, Fahmy et al. 2010). The continuous circulation of $L$. major is maintained by the highest densities of both the P. papatasi and gerbil populations after the heavy rains that are considered as favourable habitats for the survival of the vector and reservoir populations. The number of zoonotic cutaneous leishmaniasis (ZCL) cases is still underestimated due to the Bedouin traditions of preventing females to visit clinics and their dependence on leishmaniasis treatment using routine heat therapy. The mean annual cases reported to the official public health centres in North Sinai during 20062011 were 296.67 cases (Ministry of Health of Egypt, unpublished observations), with the highest infection rate reported during 2008-2010 due to a change in environmental conditions. Toward the end of this period, the incidence of ZCL caused by L. major decreased after control efforts for both vectors and rodent reservoirs by the Egyptian Ministry of Health. Due to such continuous disease dynamics in response to environmental changes, we plan in our future research to investigate the potential role of rodent populations in the circulation of the parasite in the Sinai, to study in detail the coarse-resolution ecology and to study the biogeography of disease through mapping exercises and site suitability analysis using efficient quantitative techniques.

\section{ACKNOWLEDGEMENTS}

To Dr Awni F Sallem, for his kind help during the field trips, and to Townsend Peterson, University of Kansas, for his comments that improved the paper.

\section{REFERENCES}

Campbell-Lendrum D, Dujardin J-P, Martinez E, Feliciangeli MD, Perez JE, de Silans LNMP, Desjeux P 2001. Domestic and peridomestic transmission of American cutaneous leishmaniasis: changing epidemiological patterns present new control opportunities. Mem Inst Oswaldo Cruz 96: 159-162.

CIOMS - Council for International Organizations of Medical Sciences 1985. International guiding principles for biomedical research involving animals. Altern Lab Anim 12: ii.

Depaquit J, Léger N, Ferté H 1998. The taxonomic status of Phlebotomus sergenti Parrot, 1917, vector of Leishmania tropica (Wright, 1903) and Phlebotomus similis Perfiliev, 1963 (Diptera - Psychodidae). Morphologic and morphometric approaches. Biogeographical and epidemiological corollaries. Bull Soc Pathol Exot 91: 346-352.

El Tai NO, Osman OF, El Fari M, Presber W, Schönian G 2000. Genetic heterogeneity of ribosomal internal transcribed spacer (ITS) in clinical samples of Leishmania donovani spotted on filter paper as revealed by single-strand conformation polymorphisms (sscp) and sequencing. Trans R Soc Trop Med Hyg 94: 1-5.

Fahmy AR, Samy AM, Doha SA, Shehata MG 2010. Preliminary field investigations on Phlebotomine sandflies (Diptera: Psychodidae) from a recent cutaneous leishmaniasis focus in Northern-Sinai, Egypt. Egypt Acad J Biolog Sci 2: 9-15.

Faulde M, Schrader J, Heyl G, Amirih M 2008. Differences in transmission seasons as an epidemiological tool for characterization of anthroponotic and zoonotic cutaneous leishmaniasis in northern Afghanistan. Acta Trop 105: 131-138.

Fryauff DJ, Modi GB, Mansour NS, Kreutzer RD, Soliman S, Youssef FG 1993. Epidemiology of cutaneous leishmaniasis at a focus monitored by the multinational force and observers in the northeastern Sinai Desert of Egypt. Am J Trop Med Hyg 49: 598-607.

Hamadto HA, Al FA, Farrag AB, Maksoud MKA, Morsy TA 2007. Zoonotic cutaneous leishmaniasis: reservoir host and insect vector in north Sinai, Egypt. J Egypt Soc Parasitol 37: 843-850.

Jacobson RL 2003. Leishmania tropica (Kinetoplastida: Trypanosomatidae) - a perplexing parasite. Folia Parasitol (Praha) 50: 241-250.

Jacobson RL, Eisenberger CL, Svobodova M, Baneth G, Sztern J, Carvalho J, Nasereddin A, Fari ME, Shalom U, Volf P, Votypka J, Dedet J-P, Pratlong F, Schönian G, Schnur LF, Jaffe CL, Warburg A 2003. Outbreak of cutaneous leishmaniasis in northern Israel. J Infect Dis 188: 1065-1073.

Kamal HA, Doha SA, El-Hosary SS, Shehata MG, El Sawaf BM 2003. Human zoonotic cutaneous leishmaniasis and associated sandflies (Diptera: Psychodidae) in Sheikh Atiya village, southern Sinai, Egypt. J Egypt Soc Parasitol 33: 795-803.

Katakura K 2009. Molecular epidemiology of leishmaniasis in Asia (focus on cutaneous infections). Curr Opin Infect Dis 22: 126-130.

Lane RP 1986. The sandflies of Egypt (Diptera: Phlebotominae). Bull Br Mus Nat Hist (Ent) 52: 1-35.

McAleece N, Gage JDG, Lambshead PJD, Paterson GLJ 1997. Biodiversity professional. Beta-Version. The Natural History Museum and the Scottish Association for Marine Sciences, London.

Mebrahtu YB, Lawyer PG, Ngumbi PM, Kirigi G, Mbugua J, Gachihi G, Wasunna K, Pamba H, Sherwood JA, Koech DK 1992. A new rural focus of cutaneous leishmaniasis caused by Leishmania tropica in Kenya. Trans R Soc Trop Med Hyg 86: 381-387. 
Miranda A, Carrasco R, Paz H, Pascale JM, Samudio F, Saldaña A, Santamaría G, Mendoza Y, Calzada JE 2009. Molecular epidemiology of American tegumentary leishmaniasis in Panama. Am J Trop Med Hyg 81: 565-571.

Morsy TA, Merdan AI, Wahba MM 1992. Leishmania infection sought in rodents in north Sinai, Egypt. J Egypt Soc Parasitol 22: 357-363.

Nasereddin A, Bensoussan-Hermano E, Schönian G, Baneth G, Jaffe CL 2008. Molecular diagnosis of Old World cutaneous leishmaniasis and species identification by use of a reverse line blot hybridization assay. J Clin Microbiol 46: 2848-2855.

Osborn DJ, Helmy I 1980. The recent land mammals of Egypt (including Sinai). Fieldiana Zool NS 5: xix+1-579.

Parmesan C 2006. Ecological and evolutionary responses to recent climate change. Annu Rev Ecol Evol Syst 37: 637-669.

Reithinger R, Dujardin JC, Louzir H, Pirmez C, Alexander B, Brooker S 2007. Cutaneous leishmaniasis. Lancet Infect Dis 7: 581-596.

Rodríguez-Barraquer I, Góngora R, Prager M, Pacheco R, Montero LM, Navas A, Ferro C, Miranda MC, Saravia NG 2008. Etiologic agent of an epidemic of cutaneous leishmaniasis in Tolima, Colombia. Am J Trop Med Hyg 78: 276-282.

Saliba FK, Disi AM, Ayed RE, Saleh N, Al Younes H, Oumesh O, Al Ouran R 1994. Rodents as reservoir hosts of cutaneous leishmaniasis experimentally infected mice and naturally infected in Jordan. Ann Trop Med Parasitol 88: 617-622.

Samy AM 2009. Sandfly vectors and rodent reservoirs responsible for leishmaniasis transmission in a remote area of North Sinai (Egypt), MsD Thesis, Ain Shams University, Cairo, 96 pp.

Schwenkenbecher JM, Wirth T, Schnur LF, Jaffe CL, Schallig H, Al-Jawabreh A, Hamarsheh O, Azmi K, Pratlong F, Schönian G 2006. Microsatellite analysis reveals genetic structure of Leishmania tropica. Int J Parasitol 36: 237-246.

Seaman J, Mercer AJ, Sondorp HE, Herwaldt BL 1996. Epidemic visceral leishmaniasis in southern Sudan: treatment of severely debilitated patients under wartime conditions and with limited resources. Ann Intern Med 124: 664-672.
Shehata MG, El Said S, Beier JC, Kenawy MA, Gwadz R, Shabaan M 1988. Immunological detection of Plasmodium falciparum circumsporozite antigens in Anopheles sergentii from Egypt. $J$ Egypt Public Health Assoc 63: 215-218.

Shehata MG, Samy AM, Doha SA, Fahmy AR, Kaldas RM, Furman BD, Villinski JT 2009. First report of Leishmania tropica from a classical focus of L. major in North Sinai, Egypt. Am J Trop Med Hyg 81: 213-218.

Soliman MF 2006. The persistence, dissemination and visceralization tendency of Leishmania major in Syrian hamsters. Acta Trop 97: 146-150.

Svobodova M, Votypka J, Peckova J, Dvorak V, Nasereddin A, Baneth G, Sztern J, Kravchenko V, Orr A, Meir D, Schnur LF, Volf P, Warburg A 2006. Distinct transmission cycles of Leishmania tropica in 2 adjacent foci, northern Israel. Emerg Infect Dis 12: 1860-1868.

Tibayrenc M 2005. Bridging the gap between molecular epidemiologists and evolutionists. Trends Microbiol 13: 575-580.

Vinitsky O, Ore L, Habiballa H, Cohen-Dar M 2010. Geographic and epidemiologic analysis of the cutaneous leishmaniasis outbreak in northern Israel, 2000-2003. Isr Med Assoc J 12: 652-656.

Wahba MM, Schnur LF, Morsy TA, Merdan A 1990. The characterization of Leishmania major from Phlebotomus papatasi (Scopoli) caught in northern Sinai, Egypt. Trans $R$ Soc Trop Med Hyg 84: $785-786$.

Wang J-Y, Gao C-H, Yang Y-T, Chen H-T, Zhu X-H, Lu S, Chen S-B, Tong S-X, Steinmann P, Ziegelbauer K, Zhou X-N 2010. An outbreak of the desert sub-type of zoonotic visceral leishmaniasis in Jiashi, Xinjiang Uygur Autonomous Region, People's Republic of China. Parasitol Int 59: 331-337.

WHO - World Health Organization 2008. Report of the consultative meeting on cutaneous leishmaniasis. Available from: who.int/ leishmaniasis/resources/Cutaneous_leish_cm_2008.pdf.

WHO - World Health Organization 2010. Control of the leishmaniasis. Available from: whqlibdoc.who.int/trs/WHO_TRS_949 eng.pdf. 
Annual means of climatological factors prevailed in North Sinai, Egypt (based on data of El Arish weather station)

\begin{tabular}{lcccc}
\hline Year & $\begin{array}{c}\text { Temperature } \\
\left({ }^{\circ} \mathrm{C}\right)\end{array}$ & $\begin{array}{c}\text { Relative humidity } \\
(\%)\end{array}$ & $\begin{array}{c}\text { Precipitation amount } \\
(\mathrm{mm})\end{array}$ & $\begin{array}{c}\text { Wind speed } \\
(\mathrm{Km} / \mathrm{h})\end{array}$ \\
\hline 2005 & 20.22 & 66.47 & 2.75 & 8.78 \\
2006 & 20.01 & 67.79 & 12.57 & 7.66 \\
2007 & 20.38 & 68.00 & 10.10 & 6.83 \\
2008 & 20.55 & 66.18 & 11.89 & 6.99 \\
2009 & 20.675 & 64.43 & 2.79 & 9.41 \\
2010 & 21.67 & 66.08 & 4.09 & 8.84 \\
2011 & 20.36 & 66.50 & 5.63 & 8.68 \\
Mean \pm SD & $20.62 \pm 0.54$ & $66.49 \pm 1.19$ & $7.12 \pm 4.29$ & $8.17 \pm 1.01$ \\
\hline
\end{tabular}

SD: standard deviation.

The samples collected from the sandfly Phlebotomus papatasi and the rodent species collected from different districts of North Sinai, their sources, locations and the restriction fragment length polymorphism-polymerase chain reaction (PCR) results

\begin{tabular}{|c|c|c|c|c|}
\hline Species & District & $\begin{array}{l}\text { Decimal longitude } \\
\text { (DD) }\end{array}$ & $\begin{array}{l}\text { Decimal latitude } \\
\text { (DD) }\end{array}$ & PCR results \\
\hline P. papatasi & Rafah & 34.39778 & 30.96333 & Leishmania major \\
\hline P. papatasi & Rafah & 34.20000 & 31.01667 & L. major \\
\hline P. papatasi & Rafah & 34.20000 & 31.01667 & L. major \\
\hline P. papatasi & Rafah & 34.20000 & 31.01667 & L. major \\
\hline P. papatasi & Beer Lehfen & 33.61758 & 30.60847 & L. major \\
\hline P. papatasi & Beer Lehfen & 33.61758 & 30.60847 & L. major \\
\hline Rattus norvegicus & Rafah & 34.24019 & 31.28027 & L. major \\
\hline R. norvegicus & Rafah & 34.24019 & 31.28027 & L. major \\
\hline R. norvegicus & Rafah & 34.24019 & 31.28027 & L. major \\
\hline R. norvegicus & Rafah & 34.24019 & 31.28027 & L. major \\
\hline R. norvegicus & Rafah & 34.24019 & 31.28027 & L. major \\
\hline R. norvegicus & Rafah & 34.24019 & 31.28027 & L. major \\
\hline R. norvegicus & Rafah & 34.24019 & 31.28027 & L. major \\
\hline Rattus rattus frugivorous & Beer Lehfen & 33.61758 & 30.60847 & L. major \\
\hline R. r. frugivorous & Beer Lehfen & 33.61758 & 30.60847 & L. major \\
\hline R.r.frugivorous & Beer Lehfen & 33.61758 & 30.60847 & L. major \\
\hline Rattus rattus alexandrinus & El-Hassana & 33.78393 & 30.46854 & L. major \\
\hline Gerbillus pyramidum floweri & Beer Lehfen & 33.61758 & 30.60847 & L. major \\
\hline G. p. floweri & Beer Lehfen & 33.61758 & 30.60847 & L. major \\
\hline G.p. floweri & Rafah & 34.20000 & 31.01667 & L. major \\
\hline G. p. floweri & Rafah & 34.20000 & 31.01667 & L. major \\
\hline G. p. floweri & Rafah & 34.20000 & 31.01667 & L. major \\
\hline G. p. floweri & Rafah & 34.20000 & 31.01667 & L. major \\
\hline G.p. floweri & Rafah & 34.20000 & 31.01667 & L. major \\
\hline G. p. floweri & Rafah & 34.20000 & 31.01667 & L. major \\
\hline G.p. floweri & Rafah & 34.28333 & 30.13333 & L. major \\
\hline G.p. floweri & Rafah & 34.28333 & 30.13333 & L. major \\
\hline G.p. floweri & Rafah & 34.20000 & 31.01667 & L. major \\
\hline G. p. floweri & Rafah & 34.28333 & 30.13333 & L. major \\
\hline G.p. floweri & Rafah & 34.20000 & 31.01667 & L. major \\
\hline Gerbillus andersoni & Rafah & 34.20000 & 31.01667 & L. major \\
\hline G. andersoni & Rafah & 34.20000 & 31.01667 & L. major \\
\hline G. andersoni & Rafah & 34.20000 & 31.01667 & L. major \\
\hline G. andersoni & Rafah & 34.28333 & 30.13333 & L. major \\
\hline G. andersoni & Rafah & 34.28333 & 30.13333 & L. major \\
\hline
\end{tabular}

DD: decimal degrees. 